\title{
Canada tackles antimicrobial resistance
}

$\mathrm{O}$ $\mathrm{n}$ the heels of a similar document in the US, the Canadian government has, for the first time, produced a framework for combatting antimicrobial resistance. The Canadian framework is "basically about getting our act together," said Dr. Judith Bossé, assistant deputy minister in the Infectious Disease Prevention and Control Branch in the Public Health Agency of Canada.

Antimicrobial Resistance and Use in Canada: A Federal Framework for Action identifies three strategic areas (surveillance, stewardship and innovation) and four priorities for action (establishing and strengthening surveillance systems; promoting the appropriate use of antimicrobials; enhancing the regulatory framework for veterinary medicines and medicated feed; and promoting the development of new drugs).

Leading Canadian infectious disease researchers welcomed the report, largely because it is the first stated commitment to address the problem by the federal government and finally puts Canada among other countries and nongovernmental agencies who have been sounding the alarm for years about increasing antimicrobial resistance.

The Canadian framework follows the release earlier this year of similar documents from the World Health Organization and the US Centers for Disease Control and Prevention, as well as a 2013 British strategy. It's now up to the four relevant federal government departments - the Public Health Agency of Canada, Health Canada, the Canadian Food Inspection Agency and Agriculture and Agri-Food Canada to "mobilize their own networks to start concrete planning," Bossé said.

Although there is no new money behind the federal plan, Bossé said that by requiring agencies to refocus their efforts using existing funds, "we're making some progress." If additional funds come, "it will allow us to put them where it makes the most sense."

"I'm delighted that this came out and I'm anxious to see what the details are," said Gerry Wright, director of the Michael G. DeGroote Institute for Infectious Disease Research at McMaster University in Hamilton, Ontario.

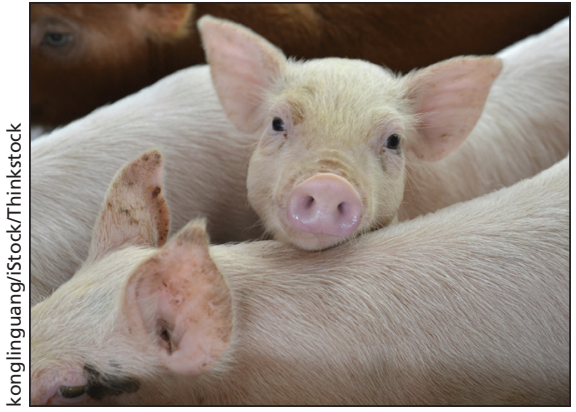

Canada will place a priority on enhancing a framework for veterinary medicines and medicated feed.

"The good news is that there is a Canadian voice on this," and it's consistent with other international plans, he said. "The silence in Canada while the rest of the world was pulling the fire alarms was heartbreaking. I've dedicated my professional life to trying to solve these problems and it made you question whether you're in the right place to have that kind of impact when everyone else seems to be manning the barricades."

Developing new drugs - as well as strategies to preserve the next generation of antibiotics - will require additional and sustained funding, Wright said. There is no money for the framework.

Dr. Lynora Saxinger said she was pleased to see the report acknowledge the need for resistance monitoring in the community, adding that she's "quite optimistic" that federal, provincial and territorial cooperation can be achieved to coordinate and standardize it.

"I can find timely antimicrobial resistance information from any European country right now faster than I can ... in Canada," said Saxinger, chair of the Antimicrobial Stewardship and Resistance Committee for the Association of Medical Microbiology and Infectious Disease Canada.

"If the European Union can do it, then I would submit that we can do it too."

She too said that dealing with antimicrobial resistance will require new funds.

But it's "very reasonable" to begin with existing resources and build on that, Saxinger added. - Terry Murray, Toronto, Ont.

CMAJ 2014. DOI:10.1503/cmaj.109-4937 